\title{
Aspirin for the prevention of colorectal cancer
}

\author{
X. Garcia-Albeniz, MD ${ }^{\mathrm{a}}$ [Research Fellow] and A.T. Chan, MD, MPH ${ }^{\mathrm{b},{ }^{*}}$ [Assistant Professor \\ of Medicine] \\ ${ }^{\text {aDepartment }}$ of Epidemiology, Harvard School of Public Health, 677 Huntington Ave., Boston, MA \\ 02114, USA \\ bGastrointestinal Unit, Massachusetts General Hospital and Harvard Medical School, 55 Fruit St., \\ Boston, MA 02114, USA
}

\begin{abstract}
Over 600,000 people worldwide die of colorectal cancer (CRC) annually, highlighting the importance of developing effective prevention strategies. Among proposed chemopreventive interventions, aspirin is perhaps the agent with the strongest body of evidence that supports wider spread use to significantly reduce the population burden of CRC. Several epidemiological studies, four randomized controlled trials (RCTs) of colorectal polyp recurrence, and RCTs in patients with hereditary colorectal cancer syndromes, have shown that aspirin reduces incidence of colorectal neoplasia. Recently, in a pooled analysis of five cardiovascular-prevention RCTs linked to cancer outcomes, daily aspirin use at any dose reduced the risk of CRC by $24 \%$ and of CRCassociated mortality by $35 \%$ after a delay of $8-10$ years. In an expanded meta-analysis of 8 cardiovascular-prevention RCTs, daily aspirin use at any dose was associated with a $21 \%$ lower risk of all cancer death, including CRC, with benefit only apparent after 5 years. In this review, we will summarize human studies of aspirin in CRC prevention as well as discuss the safety profile and mechanism of aspirin in CRC prevention.
\end{abstract}

\section{Keywords}

Aspirin; NSAID; Colorectal cancer; Adenocarcinoma; Adenoma

\section{Introduction}

Despite increasing efforts in many countries to reduce the incidence of colorectal cancer (CRC) through population-based screening, over 600,000 men and women worldwide die of $\mathrm{CRC}$ each year [1]. Screening reduces CRC mortality and is recommended beginning at age 50 for average risk individuals, although compliance is far from adequate and not widely available in resource-poor settings [2,3]. Thus, understanding the role of agents such as aspirin for chemoprevention remains a high priority.

Aspirin has been extensively researched in the context of the prevention of cardiovascular (CV) disease. Both patients and physicians are largely familiar with the long-term use of aspirin for chronic disease prevention. Moreover, risk factors for CRC and cardiovascular disease, such as older age, overweight/obesity, and physical inactivity, are shared. Thus, the

(c) 2011 Elsevier Ltd. All rights reserved.

*Corresponding author.xgarciad@hsph.harvard.edu (X. Garcia-Albeniz), achan@partners.org (A.T. Chan). .

Conflict of interest XGA has no conflict of interest to declare. ATC has previously served as a consultant to Bayer HealthCare,

Millennium Pharmaceuticals, and Pfizer Inc. 
ability of aspirin to provide dual benefit for patients with significant risk factors for both CV disease and CRC holds strong appeal.

The widespread use of aspirin for $\mathrm{CV}$ prevention as well as compelling in vitro and in vivo experimental data supporting its anti-neoplastic benefit has led to extensive examination of aspirin for cancer prevention in human populations. In this review, we will provide an overview of the human data that supports a role of aspirin as a chemopreventive agent for CRC. We will consider both observational and randomized clinical trial (RCT) evidence of aspirin's effect on both colorectal adenoma, the precursor for the vast majority of invasive adenocarcinoma, and CRC. We also discuss issues regarding the optimal dose of aspirin in the context of its known side effects as well as its potential mechanism of action.

\section{Evidence arising from observational studies of sporadic CRC}

The vast majority of cohort and case-control studies have observed an inverse association between aspirin use and risk of CRC [4]. An early analysis of 662,424 men and women enrolled in the U.S. Cancer Prevention Study (CPS) II cohort showed that aspirin use at least 16 times per month was associated with a $40 \%$ reduced risk of colon cancer mortality over a 6-year period [5]. An updated analysis of this cohort observed that daily use of at least 325 $\mathrm{mg}$ for at least 5 years was associated with a lower incidence of CRC compared with nonusers (rate ratio [RR], 0.68; 95\% confidence interval [CI], 0.52- 0.90), as well as reduced risks of other cancers [6]. In a separate cohort study of 47,363 male US health professionals, the Health Professionals Follow-up Study (HPFS), regular aspirin use ( $\geq 2$ times/week) was associated with a $21 \%$ (RR, $0.79 ; 95 \%$ CI, 0.69-0.90) lower risk of CRC over 18 years of follow-up [7]. Similar findings were observed in the US Nurses' Health Study (NHS) cohort. In 82,911 women enrolled in the NHS, regular aspirin use ( $\mathrm{mg}$ tablets/week) was associated with a $23 \%$ reduced risk of CRC (RR, 0.77; 95\% CI, 0.670.88) over 20 years of follow-up [8]. In the National Institutes of Health (NIH) AARP study of 301,240 older United States men and women (mean age 62.8 years), a lower risk of CRC was seen among both weekly users (RR, 0.88 ; 95\% CI, 0.80-0.97) and daily users (RR, $0.86 ; 95 \%$ CI, 0.79-0.94) of aspirin compared with nonusers [9]. Smaller cohort studies and a large number of case- control studies have reported very consistent associations [4].

Aspirin has also been associated with a lower risk of death from CRC. In an analysis of the NHS, regular aspirin use was significantly associated with a $28 \%$ reduction (hazard ratio $[\mathrm{HR}]=0.72,95 \%$ CI $0.56-0.92)$ in risk of death from CRC, a $12 \%$ reduction in risk of death from any cancer $(\mathrm{HR}=0.88 ; 95 \% \mathrm{CI} 0.81-0.96)$, and a $25 \%$ reduction in risk of death from all causes (HR=0.75, 95\% CI 0.71-0.81) [10]. The latent period for the reduction in cancer deaths was at least 10 years, in contrast with the latent period for the reduction of $\mathrm{CV}$ mortality, which was 1-5 years of aspirin use. This finding is consistent with present understanding of the relatively abbreviated time frame within which thrombosis and platelet aggregation may lead to vascular events in comparison with the longer time frame associated with the slow-wise progression of normal colonic mucosa to adenoma to cancer.

Observational data on the influence of aspirin use on survival has also been examined among patients with established CRC. Among 1,279 male and female health professionals diagnosed with CRC (stage I-III), aspirin use after diagnosis was associated with a lower risk of CRC-specific and overall mortality [11]. During a median follow-up of 11.8 years, the HR (adjusted for cancer stage and location, sex, age, and body mass index) for CRC mortality was lower in aspirin users compared with nonusers (RR, 0.71; 95\% CI, 0.53-0.95). The effect of aspirin on disease-free survival and disease recurrence has also been examined in the Cancer and Leukaemia Group B (CALGB) 89803, a randomized, multicenter study originally designed to compare regimens of adjuvant 5-fluorouracil/leucovorin (5-FU/LV) 
with or without irinotecan in 830 patients with stage III colon cancer. Within this trial, disease recurrence was lower among patients who reported consistent aspirin use compared with nonuse (HR, 0.45; 95\% CI, 0.21-0.97) [12]. Two additional cohort studies that only assessed aspirin use patterns before diagnosis observed that prediagnosis aspirin use was associated with lower CRC-specific mortality $[13,14]$.

\section{Evidence arising from randomized clinical trials}

Recently Rothwell et al linked data on cancer outcomes to RCTs originally designed to examine the effect of aspirin on cardiovascular (CV) disease prevention [15]. An initial pooled analyses of individual patient data including four such trials, which each enrolled at least 1,000 subjects assigned to daily aspirin treatment for at least 2.5 years: two primary prevention trials (British Doctor's Trial and Thrombosis Prevention Trial) and two secondary prevention trials (Swedish Aspirin Low-dose Trial and UK-Transient Ischaemic Attack) [16-19]. These trials examined both patient populations at low CV risk $(n=10,224)$ $[16,17]$ as well as individuals with higher risk (history of transient ischaemic attack, minor stroke, or retinal artery occlusion $(n=3809))[18,19]$. The aspirin doses ranged from 75 to $1200 \mathrm{mg} /$ day ( 3 of the 4 trials were placebo controlled), with a median treatment duration of 2.6-6.9 years. Among the combined 4 studies, 391 cases of CRC were documented over a median follow-up of 18.3 years. Treatment with any aspirin dose between 75 and $500 \mathrm{mg} /$ day reduced the 20 -year risk of colon cancer by $24 \%$ and CRC-associated mortality by $35 \%$, with increasing benefit observed with longer durations of treatment. There was a suggestion that the reduction in CRC incidence may be largely confined to the proximal colon (HR, $0.45 ; 95 \%$ CI, 0.28-0.74) compared with the distal colon (HR, 1.10; 95\% CI, 0.73- 1.64) $(P$ for difference $=0.04$ ). There was no overall effect of aspirin on the risk of rectal cancer (HR, 0.90; 95\% CI, 0.63-1.30), although there appeared to be a reduced risk (HR, 0.47; 95\% CI, $0.26-0.87, P=0.01$ ) among those with treatment duration of at least 5 years.

Another study by Rothwell et al pooled individual patient data and examined the effects of randomized aspirin treatment on mortality due to all cancers [20] (See Table 1). The analysis included data from 8 cardiovascular-prevention RCTs of daily aspirin (7 placebo controlled) with an initial scheduled trial treatment period of at least 4 years $[16,17,19,21-25]$. Three of the studies enrolled 7526 patients with type 1 or type 2 diabetes mellitus [21,23,24]. RCTs of aspirin administered on alternate days were not included [26,27]. Among the 8 trials with a total of 25,570 patients and 674 cancer-related deaths during the trial periods, aspirin treatment at a dose ranging from 75 to $1200 \mathrm{mg} /$ day was associated with a $21 \%$ lower risk of death from any cancer during the in-trial follow-up period (HR, 0.79; 95\% CI, $0.68-0.92, P$ $=0.003)$. Benefit was only apparent after 5 years of follow-up (HR, 0.66; 95\% CI, 0.50 $0.87, P=0.003$ ), with the absolute reduction in 20 -year risk of cancer death reaching $7.08 \%$ (95\% CI, 2.42\%-11.74\%) at age 65 years. Among the 6 trials with data on the specific site of cancer occurrence, patients randomized to aspirin had a reduced risk of death due to CRC (HR, $0.41 ; 95 \%$ CI, $0.17-1.00, P=0.05$ ), beginning 5 years after the initiation of aspirin treatment.

Although these data are compelling, a limitation of these analyses is that the included studies were cardiovascular prevention trials not originally designed to examine cancer incidence or mortality. Hence, ascertainment of cancer-related endpoints may be less complete or accurate than would be expected in a clinical trial with pre-specified cancer outcomes. Moreover, for some RCTs, cancer outcomes were based upon post-trial follow-up of patients through linkage with death certificates or cancer registries. As a result, there was no information collected regarding post-trial usage of aspirin or nonaspirin NSAIDs or cancer screening. It is conceivable, for example, that patients who were previously treated with aspirin were more vigorously screened due to a greater prevalence of anaemia associated 
with aspirin. Last, the two largest RCTs of aspirin, the Physicians' Health Study (PHS) and Women's Health Study (WHS) did not demonstrate a reduction in CRC incidence [26,27]. The PHS was a randomized, placebo-controlled trial designed to determine the effect of aspirin $325 \mathrm{mg} /$ every other day on CV disease in 22,071 healthy male physicians. The WHS examined the effect of aspirin $100 \mathrm{mg} /$ every other day on CV events and overall cancer incidence in 39,876 initially healthy women. There was no effect of aspirin on the incidence of CRC over a 10-year follow-up in either trial; the RR of CRC was 1.03 (95\% CI, 0.831.28 ) in the PHS and 0.97 (95\% CI, 0.77-1.24) in the WHS [28,29].

There are a few explanations for the contrasting results of the PHS and WHS compared with the Rothwell et al meta-analyses. First, both the PHS and WHS studies used alternate-day dosing regimens, in contrast to the daily dosing used in the studies included by Rothwell et al. It is conceivable that alternate-day dosing may be less effective than daily dosing in inhibiting carcinogenesis, although such differences are not well-established. Second, the duration of follow-up in both the PHS and WHS studies may have been insufficient to detect a difference in CRC incidence. In their meta-analysis determining CRC incidence [15], Rothwell et al noted at least a 7-year delay after initiation of aspirin treatment before a reduction in CRC incidence even began to appear, with a clear reduction not evident until more than 10 years. Thus, it is possible that longer follow-up of the WHS or PHS may demonstrate a potential protective benefit. Last, in the WHS, the equivalent daily dose of aspirin was $50 \mathrm{mg} /$ day, lower than the $75 \mathrm{mg} /$ day shown to be effective in both metaanalyses.

The benefit of aspirin use in CRC prevention has also been extrapolated from RCTs of aspirin in the prevention of adenomas, the precursors of the vast majority of CRC.

Adenomas can be a useful surrogate endpoint for CRC prevention since their development is considerably shorter than the evolution of CRC, which is believed to require at least 5-10 years. To date, there have been 4 RCTs examining the effect of aspirin on recurrent adenoma among patients with a history of prior colorectal neoplasia. First, Sandler and colleagues showed in RCT of patients with a history of nonmetastatic CRC cancer after resection of their primary tumour that daily treatment with standard-dose $(325 \mathrm{mg})$ aspirin was associated with a $35 \%$ (RR, $0.65,95 \%$ CI $0.46-0.91$ ) reduction in risk of recurrent adenoma or carcinoma at 3 years [30]. Three additional RCTs have examined the effects of aspirin in nearly 3000 patients with either a history of colorectal adenoma or previous CRC [31-33]. A meta-analysis of these trials showed that aspirin at any dose (81-325 mg/day) reduced the risk of any colorectal adenoma (defined as occurrence after randomization) by $17 \%$ (RR, 0.83 ; 95\% CI, 0.72-0.96) over a median postrandomization follow-up of 33 months [34]. The risk of advanced colorectal adenomas (defined as $1 \mathrm{~cm}$ or larger in size or with tubulovillous or villous histology, high-grade dysplasia, or invasive cancer) was reduced by $28 \%$ (RR, $0.72 ; 95 \% \mathrm{CI}, 0.57-0.90$ ). Of note, this meta-analysis included results after one year of follow-up in one of the RCTs, the Association pour la Prevention par l'Aspirine du Cancer Colorectal Study Group (APACC) Trial, which randomized 272 with colorectal adenomas to receive soluble lysine acetylsalicylate $160 \mathrm{mg} /$ day, $300 \mathrm{mg} /$ day or placebo. At one year, treatment with either dose of aspirin was associated with a significant reduction in risk of recurrent adenoma at one year [32]. However, updated results after four years of follow-up did not observe any statistically significant reduction in adenoma recurrence [35]. The divergent results may be due to a high drop-out rate at 4 years (32\%). Additional studies are ongoing, including the Japan Colorectal Aspirin Polyps Prevention (JCAPP) study, an RCT examining the effect of aspirin $100 \mathrm{mg} /$ day on occurrence of recurrent tumours 2 years after endoscopic removal of colorectal adenomas and cancers in a Japanese population [36]. 
Aspirin has also been examined in an RCT among patients with familial adenomatous polyposis (FAP). The prevalence of FAP is low, associated with less than $2 \%$ of cases of CRC. However, a germline mutation in the adenomatous polyposis coli (APC) gene underlies FAP and is a primary molecular event in up to $85 \%$ of sporadic cancers; thus, chemoprevention studies in these patients have relevance for colorectal carcinogenesis in the general population. In classic FAP, patients typically develop hundreds to thousands of adenomatous polyps throughout the colon, often beginning as early as the second decade of life. Colorectal adenocarcinomas inevitably develop in FAP patients, typically by age 40 years, or approximately 10-15 years after the initial appearance of polyposis [37]. Agents that can delay adenoma development or growth and progression to cancer could play a vital role in delaying prophylactic colectomy and preventing polyposis in a retained rectum or ileoanal pouch after colectomy [36]. Early RCTs have demonstrated the efficacy of the nonsteroidal anti-inflammatory drug (NSAID), sulindac, as well as the cyclooxygenase-2 (COX-2) selective inhibitors, celecoxib and rofecoxib, in reducing the mean size of colorectal polyps and the mean number of colorectal polyps after 6-9 months of treatment in FAP patients [38-40]. Aspirin has been studied in the Colorectal Adenoma/ carcinoma Prevention Programme 1 (CAPP1) study, an RCT of aspirin $600 \mathrm{mg} /$ day and/or resistant starch $30 \mathrm{~g} /$ day in a 2-by-2 factorial design. Among 133 evaluable patients, aspirin treatment resulted in a non-significant reduction in polyp number $(\mathrm{RR}=0.77$; 95\% CI, $0.54-1.10)$ compared with non-aspirin, and a significant reduction in polyp size among patients treated with aspirin for more than 1 year [41]. The efficacy of lower doses of aspirin (100 mg/day) in FAP patients is currently being explored in the Japan Familial Adenomatous Polyposis Prevention II (J-FAPP II) trial.

The other major known distinct genetic syndrome that underlies familial CRC is the Lynch syndrome, an autosomal dominantly inherited condition in which germline mutations in mismatch repair genes confer a high lifetime risk of cancers of the colorectum as well as other organs. It is estimated that $1-5 \%$ of CRC cases arise as a result of Lynch syndrome [42]. Understanding the role of aspirin in this high-risk group with germline susceptibility is relevant to the 1 in $6 \mathrm{CRCs}$ in which acquired silencing of a mismatch repair gene is the primary molecular driver of carcinogenesis. The CAPP2 RCT was the first aspirin study to have CRC prevention as a primary end point. Of the 1007 eligible carriers randomized, 937 patients with Lynch syndrome began treatment and were the basis for analysis. Analysis at the end of the intervention phase showed that aspirin did not reduce the risk of colorectal adenoma or carcinoma over a mean treatment duration of 29 months [43]. The study design also included a longer, double-blinded, postintervention follow-up with a re-analysis of cancer incidence performed when the first participants reached a follow-up of 10 years [44]. In this analysis, among 861 individuals with a mean follow-up of 56 months, CRC (not combined with adenomas) developed in fewer aspirin (4.2\%) than non-aspirin (6.9\%) patients (HR, 0.63; 95\% CI, 0.35-1.13; $P=0.12$ ) in an intent-to-treat (ITT) analysis, and significantly fewer (HR, $0.41 ; 95 \% \mathrm{CI}, 0.19-0.86 ; P=0.02)$ in a prespecified per-protocol analysis (in about $30 \%$ of long-term patients; aspirin treatment for two years ascertained by extrapolated tablet counts). Aspirin had a lower CRC risk (incidence-rate ratio $=0.56 ; 95 \%$ CI, 0.32-0.99; $P=0.05$ ) in ITT analyses accounting for multiple primary CRCs in some individuals. These results are a striking contrast to the initial/shorter-term findings, suggesting that aspirin is effective in reducing CRC risk among this high-risk population. However, these results need to be interpreted in light of certain limitations. For example, endpoint ascertainment was not standardized. It is possible that more intensive colonoscopic evaluation may have occurred in the aspirin group due to more-frequent adverse effects observed postintervention (e.g. anaemia associated with aspirin treatment). 


\section{Optimal dose and duration}

Because the adverse effects of aspirin appear to be largely dose related as noted above, the minimally effective dose required for CRC prevention remains a critically important question. In evidence arising from cardiovascular RCTs, it appears that the effect of daily aspirin appears to be relatively dose-independent, with efficacy observed even with relatively low doses. For example, the Rothwell meta-analyses found that typical regimens of daily aspirin used for vascular disease prevention (75-325 mg daily) were as effective as high-dose (1200 mg/day) aspirin. The HR for CRC associated with $75 \mathrm{mg}$ of aspirin in two RCT was 0.76 (95\% CI 0.52-1.10), which was not significantly different from the overall $\mathrm{HR}$ for CRC for any dose of aspirin (75-325 mg daily) of 0.76 (95\% CI 0.63-0.94) [15]. The adenoma recurrence trials also suggest that aspirin doses in the range of 81-325 $\mathrm{mg}$ daily reduce risk. However, the dose-response patterns in the studies are difficult to reconcile. Two trials compared higher (300-325 mg/day) and lower ( $81-160 \mathrm{mg} /$ day) doses of aspirin; a reduction in the risk of all recurrent adenomas was found only with the lower (81-160 mg/day) doses [34]. Nonetheless, two other trials that only studied the higher (300$325 \mathrm{mg} /$ day) doses of aspirin both reported reductions in risk of all adenomas from the active treatment. Over all trials, the summary estimates for the risk reduction associated with lower $(81-160 \mathrm{mg}$ ) and higher (300-325 mg) dose aspirin were similar both for all adenomas and for advanced adenomas. In contrast, data from the two trials of alternate-day aspirin that were not included in the meta-analysis (i.e., aspirin $325 \mathrm{mg}$ in the PHS study and $100 \mathrm{mg}$ in the WHS study) did not show a reduction in risk of CRC [26,27]. Although the negative findings of these studies could be attributed to their relatively short follow-up and/ or alternate-day dosing, these studies are notable counterweights to the other studies that support the efficacy of low-dose aspirin.

Observational data are not clear if relatively low doses of aspirin are effective, with several studies suggesting that $300-325 \mathrm{mg} /$ day may be required [4,6-8,45]. Unfortunately, in most of these observational studies, information regarding use patterns is incomplete, and many of the analyses of dose-response patterns have not taken into account the duration of use and the follow-up apparently required for prevention of CRC. In 2 prospective cohort studies that could examine use of aspirin over a long duration, greater efficacy was observed with intake as high as $14(325 \mathrm{mg})$ tablets per week $[7,8]$.

Additional data regarding the effectiveness of alternate-day $100 \mathrm{mg}$ aspirin may soon be available through longer-term follow-up of the WHS (N. Cook, personal communication). In addition, 2 ongoing placebo-controlled trials of aspirin ( $100 \mathrm{mg} /$ day), the Aspirin in Reducing Events in the Elderly (ASPREE) study and the Aspirin to Reduce Risk of Initial Vascular Events (ARRIVE), might yield important insights, although each of these studies may not offer follow-up beyond 5 years. A dose-finding study regarding the risk-benefit balance of different aspirin doses among individuals with Lynch syndrome is currently being planned (J. Burn, personal communication).

Both observational and clinical trial data suggest that long-term use of aspirin is required to reduce the risk of CRC. In cohort studies, the trend for the benefits of aspirin to increase with a longer duration of exposure has been consistently observed [4]. An analysis of 5146 women from 7 cohort studies estimated that long-term aspirin use (about 20 years) reduced the risk of CRC by $15 \%$ (RR, 0.85; 95\% CI, 0.78-0.92) [46]. Several case-control studies have also reported a reduction in CRC risk associated with increasing duration of aspirin use [46-49]. An analysis of 9232 men from 11 case-control studies reported that aspirin use (about 20 years) reduced the risk of CRC by $41 \%$ (RR, 0.59; 95\% CI, 0.54-0.64) [46]. In RCTs, the Rothwell meta-analyses show that the longer the duration of aspirin treatment (at any dose of 75-325 mg daily) the stronger the benefit both in CRC incidence (HR, 0.69 with 
treatment for $\geq 2.5$ years, HR, 0.63 with treatment for $\geq 5$ years) and CRC mortality (HR, 0.54 with treatment for $\geq 2.5$ years, HR, 0.48 with treatment for $\geq 5$ years) $[15,20]$.

\section{Safety profile of aspirin}

On the basis of decades of widespread clinical use and evidence from cardiovascularprevention RCTs, the safety profile of aspirin is reasonably well-defined [50,51]. The most frequently reported serious adverse events associated with regular aspirin use are related to gastrointestinal (GI) bleeding. A recent meta-analysis of 35 RCTs of aspirin using doses of 75-325 mg per day estimated an HR for a major GI bleed of 1.55 (95\% CI, 1.27-1.90) compared to placebo control. For average-risk individuals, this translates into 1-2 GI bleeds per 1000 person-years [52], with a higher absolute risk among individuals with additional baseline risk factors. Some [53-55], but not all [56-58], studies have observed that such toxicities are largely dose-related, with the HR for bleeding complications generally higher at standard (300-325 mg) doses of aspirin than low (75-162.5 mg) doses [19,59-63].

Nonetheless, the risk of GI toxicity with low-dose aspirin remains significant [57]. Although the relative (RR, 1.43; 95\% CI, 0.85-2.42) and absolute (1-2 intracranial bleeds per 10,000 patient-years) risk of intracranial bleeding with low-dose aspirin use is lower than the corresponding risk of GI bleeding [57,64], the generally more severe consequences of intracranial bleeding do weight heavily in overall considerations of risk and benefit. Based on these concerns about the adverse consequences of long-term aspirin use, the United States Preventative Services Task Force (USPSTF) recommended against the routine use of aspirin for CRC prevention in average-risk population in 2007 [65]. However, such riskbenefit calculations might require reconsideration based on the recent evidence supporting a benefit of daily aspirin use in the prevention of death from several cancers, including those of the colorectum [20]. In the Rothwell et al pooled analysis of individual patient data from 8 RCTs of aspirin versus control, daily aspirin for 5-10 years, reduced in-trial cancer deaths after 5 years by $34 \%(P=0.003)$, with a $10 \%$ reduction in all-cause mortality during the trials, and reduced the 20 -year risk of cancer death by $20 \%(P<0.0001)$. Thus, for many individuals, the benefits of long-term use of daily aspirin for prevention of chronic disease may outweigh the consequences associated with the increased risk of bleeding.

\section{Mechanism of action in cancer prevention}

\section{(a) COX-1 and 2 pathways}

Aspirin's most well-characterized pharmacologic activity is the permanent modification of the prostaglandin-endoperoxide synthetase (PTGS) or COX enzymes. These enzymes are rate limiting for the conversion of arachidonic acid to prostaglandins and related eicosanoids. COX-1 isoenzyme is constitutively expressed in most tissues, whereas growth factors, oncogenes, tumour promoters, and inflammatory cytokines induce the COX-2 isoenzyme. It is reasonably well-established that aspirin's vascular benefits are largely due to acetylation of platelet-activated PTGS-1 or COX-1 that occurs even with low doses $(<75$ $\mathrm{mg}$ /day) [66]. In contrast, the mechanism of aspirin's antineoplastic effect is less clear, with substantial evidence supporting both COX-dependent and COX-independent mechanisms.

Some of the primary effectors of COX-dependent mechanisms in carcinogenesis are likely to be prostaglandins, particularly prostaglandin E2 (PGE2). PGE2 increases cellular proliferation, migration, and invasiveness, promotes angiogenesis, induces resistance to apoptosis, and modulates cellular and humoral immunity [67]. In animal models, PGE2 administration reverses aspirin-induced adenoma regression and enhances carcinogeninduced tumour incidence, whereas genetic deletion of PGE2 receptors EP1 and EP4 confers resistance to formation of aberrant crypt foci, polyps, and cancers [68]. Examination of the polyps in ApcMin/+ mice reveals that both COX-1 and COX-2 contribute to PGE2 
formation in polyps, but only COX-1 contributes to PGE2 production in normal tissue [69]. In humans, aspirin doses sufficient to inhibit COX-1 but not COX-2 [70] appear to effectively inhibit prostaglandin synthesis in the colon [71]. This suggests that, if the antineoplastic effect of aspirin is primarily mediated through the suppression of prostaglandins, inhibition of COX-1 likely plays a major role.

Nonetheless, a number of studies have directly implicated COX-2 in colorectal tumorigenesis [72,73]. In Apc $\Delta 716$ knockout mice, which mimic human FAP, deletion of the COX-2 reduced the number of intestinal polyps compared with controls [74]. Human data also support a central role for COX-2 in colorectal carcinogenesis. In a pooled analysis of two prospective cohorts, aspirin use was associated with a lower risk of CRC among COX-2 positive tumours but not COX-2 negative tumours ( $\mathrm{p}$ for heterogeneity $=0.02$ ) [75]. COX-2's influence in neoplasia may also be mediated through mechanisms other than inhibition of prostaglandin synthesis: aspirin can inhibit COX-2-dependent generation of aspirin-triggered lipoxins, which inhibit cell proliferation [76], and attenuate COX-2mediated activation of carcinogens, such as polycyclic aromatic hydrocarbons [77].

However, because aspirin inhibits COX-2 in epithelial cells at higher doses than those required to acetylate platelets, it is unclear how to integrate the findings in the secondary analyses of cardiovascular-prevention RCT that lower, anti-platelet doses aspirin (75 mg/ day) are as effective as higher doses in reducing risk of CRC. These observations could be mechanistically explained by an indirect effect of aspirin on COX-2 through inhibition of platelet activity and function. It has been hypothesised that aspirin-mediated inactivation of platelets may restore antitumour reactivity by blocking the release of paracrine lipid and protein mediators that induce COX-2 expression in adjacent nucleated cells at sites of mucosal injury [78]. EX vivo studies in human volunteers have also shown that aspirin inhibits thromboxane-mediated release of the biologically active lipid, sphingosine-1phosphate (S-1P) from platelets [79]. S-1P promotes tumour growth, neovascularization, and inflammation [80].

\section{(b) Non-COX pathways}

There are also a number of non-COX-related pathways hypothesised to mediate aspirin's anti-neoplastic effects. These include direct modulation of oncogene-induced expression of transcription factors, such as nuclear factor kappa $\mathrm{B}(\mathrm{NF \kappa B})$ and induction of spermidine/ spermine N1-acetyltransferase that modulates of polyamine catabolism [81,82]. Aspirin may also increase apoptosis of tumour cells, possibly via complex interactions with tumour promoters and suppressors and deoxyribonucleic acid (DNA) repair genes and through modulation of the Wnt/ $\beta$-catenin (ceramide) pathway. However, a significant limitation of much of the in vitro data supporting these pathways is the high doses examined, which may not be physiologically relevant in vivo. In humans, $300 \mathrm{mg} /$ day of aspirin corresponds to peak plasma levels of unchanged aspirin of less than $50 \mu \mathrm{M}$ and levels of the primary metabolite, salicylate, of less than $0.5 \mathrm{mM}$, with the great majority (>90\%) of both compounds bound to other proteins. In in vitro studies, the typical aspirin concentrations used in protein-free media are generally much higher, primarily in the low millimolar range.

Given it demonstrated efficacy, unravelling aspirin's precise mode of action may seem a matter of somewhat secondary importance. However, an improved understanding of mechanisms will inform decisions about optimal dose, frequency of administration, and combination therapy with other agents. Thus, further investigation into aspirin's anticancer mechanism continues to be a high research priority. 


\section{Conclusion}

Taking clinical trial and observational data together, there is clear evidence that aspirin in doses as low as $325 \mathrm{mg}$ per day reduces CRC risk. There is also strong evidence from secondary analyses of cardiovascular trials that daily doses as low as $75 \mathrm{mg}$ per day may be effective. In particular, the emerging data that aspirin may reduce risk of panoply of cancers suggest that an overall consideration of aspirin's benefits for all cancers and vascular disease may dominate concerns about potential hazards at either dose. Moreover, incorporation of potential benefits associated with the development of an efficacious and cost-effective means of reducing the GI risks of long-term aspirin use (e.g., concurrent administration of gastroprotective agents) will also likely require future consideration in defining optimal dosing. Last, for countries for which endoscopic screening is a routine approach for prevention, the relative cost-effectiveness of aspirin compared to screening colonoscopy or sigmoidoscopy will be an important consideration. Because substantial data suggest that colonoscopy may be have suboptimal effectiveness for the prevention of proximal CRC, a recent analysis suggested that a strategy combining low-dose aspirin with endoscopic screening was cost-effective [84].

At present, these collective data may be considered sufficiently compelling by some to warrant a broader recommendation for routine aspirin use for the prevention of CRC and perhaps other chronic diseases. For individuals at high risk of CRC, such as those with Lynch syndrome, the results of the CAPP2 trial suggest a clearer case for aspirin use. Observational studies also support a potential role for aspirin among CRC survivors, a group in which the benefits are also likely to outweigh the risks [12]. Nonetheless, as we await data from additional trials (NCT01038583 and NCT00501059) and longer-term follow-up of trials such as the WHS and PHS, the impressive collection of evidence that has emerged since the last USPSTF recommendations do move us another step closer to broadening recommendations for aspirin use. Moreover, future evidence-based guidelines for aspirin prophylaxis can no longer consider the use of aspirin for the prevention of vascular disease in isolation from the prevention of cancer $[65,83]$.

\section{Acknowledgments}

XGA is supported by a 'La Caixa' fellowship. ATC is a Damon Runyon Cancer Foundation Clinical Investigator and supported by NCI R01 CA137178.

\section{References}

[1]. [cited 2011 Oct 4] GLOBOCAN [Internet]. 2008. Available from: http://globocan.iarc.fr

[2]. Shapiro JA, Seeff LC, Thompson TD, et al. Colorectal cancer test use from the 2005 National Health Interview Survey. Cancer Epidemiology, Biomarkers \& Prevention. Jul; 2008 17(7): 1623-30.

[3]. US Preventive Services Task Force. Screening for colorectal cancer: U.S. Preventive Services Task Force recommendation statement. Annals of Internal Medicine. Nov 4; 2008 149(9):62737. [PubMed: 18838716]

[4]. Flossmann E, Rothwell PM. Effect of aspirin on long-term risk of colorectal cancer: consistent evidence from randomised and observational studies. Lancet. May 12; 2007 369(9573):1603-13. [PubMed: 17499602]

[5]. Thun MJ, Namboodiri MM, Heath CW. Aspirin use and reduced risk of fatal colon cancer. The New England Journal of Medicine. Dec 5; 1991 325(23):1593-6. [PubMed: 1669840]

[6]. Jacobs EJ, Thun MJ, Bain EB, et al. A large cohort study of long-term daily use of adult-strength aspirin and cancer incidence. The New England Journal of Medicine. Apr 18; 2007 99(8):60815. 
[7]. Chan AT, Giovannucci EL, Meyerhardt JA, et al. Aspirin dose and duration of use and risk of colorectal cancer in men. Gastroenterology. Jan; 2008 134(1):21-8. [PubMed: 18005960]

[8]. Chan AT, Giovannucci EL, Meyerhardt JA, et al. Long-term use of aspirin and nonsteroidal antiinflammatory drugs and risk of colorectal cancer. JAMA. Aug 24; 2005 294(8):914-23. [PubMed: 16118381]

[9]. Ruder EH, Laiyemo AO, Graubard BI, et al. Non-steroidal anti-inflammatory drugs and colorectal cancer risk in a large, prospective cohort. The American Journal of Gastroenterology. Jul; 2011 106(7):1340-50. [PubMed: 21407185]

[10]. Chan AT, Manson JE, Feskanich D, et al. Long-term aspirin use and mortality in women. Archives of Internal Medicine. Mar 26; 2007 167(6):562-72. [PubMed: 17389287]

[11]. Chan AT, Ogino S, Fuchs CS. Aspirin use and survival after diagnosis of colorectal cancer. JAMA. Aug 12; 2009 302(6):649-58. [PubMed: 19671906]

[12]. Fuchs C, Meyerhardt JA, Heseltine DL, et al. Influence of regular aspirin use on survival for patients with stage III colon cancer: findings from Intergroup trial CALGB 89803. Journal of Clinical Oncology. 2005; 23(16S):3530.

[13]. Coghill AE, Newcomb PA, Campbell PT, et al. Prediagnostic non-steroidal anti-inflammatory drug use and survival after diagnosis of colorectal cancer. Gut. Apr; 2011 60(4):491-8. [PubMed: 21051449]

[14]. Zell JA, Ziogas A, Bernstein L, et al. Nonsteroidal anti-inflammatory drugs: effects on mortality after colorectal cancer diagnosis. Cancer. Dec 15; 2009 115(24):5662-71. [PubMed: 19827153]

[15]. Rothwell PM, Wilson M, Elwin C-E, et al. Long-term effect of aspirin on colorectal cancer incidence and mortality: 20-year follow-up of five randomised trials. Lancet. Nov 20; 2010 376(9754):1741-50. [PubMed: 20970847]

[16]. Peto R, Gray R, Collins R, et al. Randomised trial of prophylactic daily aspirin in British male doctors. British Medical Journal (Clinical Research Ed.). Jan 30; 1988 296(6618):313-6. [PubMed: 3125882]

[17]. Thrombosis prevention trial: randomised trial of low-intensity oral anticoagulation with warfarin and low-dose aspirin in the primary prevention of ischaemic heart disease in men at increased risk. The Medical Research Council's General Practice Research. Lancet. Jan 24; 1998 351(9098):233-41. [PubMed: 9457092]

[18]. The SALT Collaborative Group. Swedish Aspirin Low-Dose Trial (SALT) of $75 \mathrm{mg}$ aspirin as secondary prophylaxis after cerebrovascular ischaemic events. Lancet. Nov 30; 1991 338(8779): 1345-9. [PubMed: 1682734]

[19]. Farrell B, Godwin J, Richards S, et al. The United Kingdom transient ischaemic attack (UK-TIA) aspirin trial: final results. Journal of Neurology, Neurosurgery, and Psychiatry. Dec; 1991 54(12): 1044-54.

[20]. Rothwell PM, Fowkes FGR, Belch JFF, et al. Effect of daily aspirin on long-term risk of death due to cancer: analysis of individual patient data from randomised trials. Lancet. Jan 1; 2011 377(9759):31-41. [PubMed: 21144578]

[21]. ETDRS Investigators. Aspirin effects on mortality and morbidity in patients with diabetes mellitus. Early Treatment Diabetic Retinopathy Study report 14. JAMA. Sep 9; 1992 268(10): 1292-300. [PubMed: 1507375]

[22]. Juul-Möller S, Edvardsson N, Jahnmatz B, et al. Double-blind trial of aspirin in primary prevention of myocardial infarction in patients with stable chronic angina pectoris. The Swedish Angina Pectoris Aspirin Trial (SAPAT) Group. Lancet. Dec 12; 1992 340(8833):1421-5. [PubMed: 1360557]

[23]. Ogawa H, Nakayama M, Morimoto T, et al. Low-dose aspirin for primary prevention of atherosclerotic events in patients with type 2 diabetes: a randomized controlled trial. JAMA. Nov 12; 2008 300(18):2134-41. [PubMed: 18997198]

[24]. Belch J, MacCuish A, Campbell I, et al. The prevention of progression of arterial disease and diabetes (POPADAD) trial: factorial randomised placebo controlled trial of aspirin and antioxidants in patients with diabetes and asymptomatic peripheral arterial disease. BMJ. Jan. 2008 337:a1840. [PubMed: 18927173] 
[25]. Fowkes FGR, Price JF, Stewart MCW, et al. Aspirin for prevention of cardiovascular events in a general population screened for a low ankle brachial index: a randomized controlled trial. JAMA. Mar 3; 2010 303(9):841-8. [PubMed: 20197530]

[26]. Steering Commitee of the Physicians' Health Study Research Group. Final report on the aspirin component of the ongoing Physicians' Health Study. The New England Journal of Medicine. 1989; 321(3):129-35. [PubMed: 2664509]

[27]. Ridker PM, Cook NR, Lee I-M, et al. A randomized trial of low-dose aspirin in the primary prevention of cardiovascular disease in women. The New England Journal of Medicine. Mar 31; 2005 352(13):1293-304. [PubMed: 15753114]

[28]. Cook NR, Lee I-M, Gaziano JM, et al. Low-dose aspirin in the primary prevention of cancer: the Women's Health Study: a randomized controlled trial. JAMA. Jul 6; 2005 294(1):47-55. [PubMed: 15998890]

[29]. Gann PH, Manson JE, Glynn RJ, et al. Low-dose aspirin and incidence of colorectal tumors in a randomized trial. The New England Journal of Medicine. Aug 4; 1993 85(15):1220-4.

[30]. Sandler RS, Halabi S, Baron JA, et al. A randomized trial of aspirin to prevent colorectal adenomas in patients with previous colorectal cancer. The New England Journal of Medicine. Mar 6; 2003 348(10):883-90. [PubMed: 12621132]

[31]. Baron JA, Cole BF, Sandler RS, et al. A randomized trial of aspirin to prevent colorectal adenomas. The New England Journal of Medicine. Mar 6; 2003 348(10):891-9. [PubMed: 12621133]

[32]. Benamouzig R, Deyra J, Martin A, et al. Daily soluble aspirin and prevention of colorectal adenoma recurrence: one-year results of the APACC trial. Gastroenterology. Aug; 2003 125(2): 328-36. [PubMed: 12891533]

[33]. Logan RFA, Grainge MJ, Shepherd VC, et al. Aspirin and folic acid for the prevention of recurrent colorectal adenomas. Gastroenterology. Jan; 2008 134(1):29-38. [PubMed: 18022173]

[34]. Cole BF, Logan RF, Halabi S, et al. Aspirin for the chemoprevention of colorectal adenomas: meta-analysis of the randomized trials. The New England Journal of Medicine. Feb 18; 2009 101(4):256-66.

[35]. Benamouzig R, Uzzan B, Deyra J, et al. Prevention by daily soluble aspirin of colorectal adenoma recurrence: 4-year results of the APACC randomised trial. Gut. Sep 2.2011

[36]. Ishikawa H, Nakamura T, Kawano A, et al. Chemoprevention of colorectal cancer in Japan: a brief introduction to current clinical trials. Journal of Gastroenterology. Jan; 2009 44(Suppl. 1): 77-81. [PubMed: 19148798]

[37]. Galiatsatos P, Foulkes WD. Familial adenomatous polyposis. The American Journal of Gastroenterology. Feb; 2006 101(2):385-98. [PubMed: 16454848]

[38]. Giardiello FM, Hamilton SR, Krush AJ, et al. Treatment of colonic and rectal adenomas with sulindac in familial adenomatous polyposis. The New England Journal of Medicine. May 6; 1993 328(18):1313-6. [PubMed: 8385741]

[39]. Steinbach G, Lynch PM, Phillips RK, et al. The effect of celecoxib, a cyclooxygenase-2 inhibitor, in familial adenomatous polyposis. The New England Journal of Medicine. Jun 29; 2000 342(26):1946-52. [PubMed: 10874062]

[40]. Hallak A, Alon-Baron L, Shamir R, et al. Rofecoxib reduces polyp recurrence in familial polyposis. Digestive Diseases and Sciences. Oct; 2003 48(10):1998-2002. [PubMed: 14627347]

[41]. Burn J, Bishop DT, Chapman PD, et al. A randomized placebo-controlled prevention trial of aspirin and/or resistant starch in young people with familial adenomatous polyposis. Cancer Prevention Research (Philadelphia, Pa.). May; 2011 4(5):655-65.

[42]. Lynch HT, Lynch PM, Lanspa SJ, et al. Review of the Lynch syndrome: history, molecular genetics, screening, differential diagnosis, and medicolegal ramifications. Clinical Genetics. Jul; 2009 76(1):1-18. [PubMed: 19659756]

[43]. Burn J, Bishop DT, Mecklin J-P, et al. Effect of aspirin or resistant starch on colorectal neoplasia in the Lynch syndrome. The New England Journal of Medicine. Dec 11; 2008 359(24):2567-78. [PubMed: 19073976] 
[44]. Burn J, Gerdes AM, Macrae F, et al. Long-term effect of aspirin on cancer risk in carriers of hereditary colorectal cancer: an analysis from the CAPP2 randomised controlled trial. Lancet. in press.

[45]. Mahipal A, Anderson KE, Limburg PJ, et al. Nonsteroidal anti-inflammatory drugs and subsitespecific colorectal cancer incidence in the Iowa women's health study. Cancer Epidemiology, Biomarkers \& Prevention. Oct; 2006 15(10):1785-90.

[46]. Cuzick J, Otto F, Baron JA, et al. Aspirin and non-steroidal anti-inflammatory drugs for cancer prevention: an international consensus statement. The Lancet Oncology. May; 2009 10(5):501-7. [PubMed: 19410194]

[47]. Johnson CC, Hayes RB, Schoen RE, et al. Non-steroidal anti-inflammatory drug use and colorectal polyps in the Prostate, Lung, Colorectal, And Ovarian Cancer Screening Trial. The American Journal of Gastroenterology. Dec; 2010 105(12):2646-55. [PubMed: 20808298]

[48]. Din FVN, Theodoratou E, Farrington SM, et al. Effect of aspirin and NSAIDs on risk and survival from colorectal cancer. Gut. Dec; 2010 59(12):1670-9. [PubMed: 20844293]

[49]. Kune GA. The Melbourne Colorectal Cancer Study: reflections on a 30-year experience. The Medical Journal of Australia. 193(11-12):648-652. [PubMed: 21143050]

[50]. Sostres C, Lanas A. Gastrointestinal effects of aspirin. Nature Reviews Gastroenterology \& Hepatology. Jan; 2011 8(7):385-94.

[51]. Patrono C, Baigent C, Hirsh J, et al. Antiplatelet drugs: American College of Chest Physicians Evidence-Based Clinical Practice Guidelines. Chest (8th Edition). Jun; 2008 133(6 Suppl):199S233S. [PubMed: 18574266]

[52]. Lanas A, Wu P, Medin J, et al. Low doses of acetylsalicylic acid increase risk of gastrointestinal bleeding in a meta-analysis. Clinical Gstroenterology and Hepatology. Sep; 2011 9(9):762-8. e6.

[53]. Serebruany VL, Steinhubl SR, Berger PB, et al. Analysis of risk of bleeding complications after different doses of aspirin in 192,036 patients enrolled in 31 randomized controlled trials. The American Journal of Cardiology. May 15; 2005 95(10):1218-22. [PubMed: 15877994]

[54]. Peters RJG, Mehta SR, Fox KAA, et al. Effects of aspirin dose when used alone or in combination with clopidogrel in patients with acute coronary syndromes: observations from the Clopidogrel in Unstable Angina to Prevent Recurrent Events (CURE) study. Circulation. Oct 7; 2003 108(14):1682-7. [PubMed: 14504182]

[55]. Topol EJ, Easton D, Harrington RA, et al. Randomized, double-blind, placebo-controlled, international trial of the oral IIb/ IIIa antagonist lotrafiban in coronary and cerebrovascular disease. Circulation. Jul 29; 2003 108(4):399-406. [PubMed: 12874182]

[56]. Derry S, Loke YK. Risk of gastrointestinal haemorrhage with long term use of aspirin: metaanalysis. BMJ. Nov 11; 2000 321(7270):1183-7. [PubMed: 11073508]

[57]. McQuaid KR, Laine L. Systematic review and meta-analysis of adverse events of low-dose aspirin and clopidogrel in randomized controlled trials. The American Journal of Medicine. Aug; 2006 119(8):624-38. [PubMed: 16887404]

[58]. Steinhubl SR, Bhatt DL, Brennan DM, et al. Aspirin to prevent cardiovascular disease: the association of aspirin dose and clopidogrel with thrombosis and bleeding. Annals of Internal Medicine. Mar 17; 2009 150(6):379-86. [PubMed: 19293071]

[59]. The Dutch TIA Trial Study Group. A comparison of two doses of aspirin (30 mg vs. $283 \mathrm{mg}$ a day) in patients after a transient ischemic attack or minor ischemic stroke. The New England Journal of Medicine. Oct 31; 1991 325(18):1261-6. [PubMed: 1922220]

[60]. Roderick PJ, Wilkes HC, Meade TW. The gastrointestinal toxicity of aspirin: an overview of randomised controlled trials. British Journal of Clinical Pharmacology. Mar; 1993 35(3):219-26. [PubMed: 8471398]

[61]. Huang ES, Strate LL, Ho WW, et al. A prospective study of aspirin use and the risk of gastrointestinal bleeding in men. PloS One. Jan.2010 5(12):e15721. [PubMed: 21209949]

[62]. Huang ES, Strate LL, Ho WW, et al. Long-term use of aspirin and the risk of gastrointestinal bleeding. The American Journal of Medicine. May; 2011 124(5):426-33. [PubMed: 21531232]

[63]. Weil J, Colin-Jones D, Langman M, et al. Prophylactic aspirin and risk of peptic ulcer bleeding. BMJ. Apr 1; 1995 310(6983):827-30. [PubMed: 7711618] 
[64]. Gorelick PB, Weisman SM. Risk of hemorrhagic stroke with aspirin use: an update. Stroke. Aug; 2005 36(8):1801-7. [PubMed: 16020759]

[65]. Routine aspirin or nonsteroidal anti-inflammatory drugs for the primary prevention of colorectal cancer: U. S. Preventive Services Task Force recommendation statement. Annals of Internal Medicine. Mar 6; 2007 146(5):361-4.

[66]. Patrono C, Rodríguez LA García, Landolfi R, et al. Low-dose aspirin for the prevention of atherothrombosis. The New England Journal of Medicine. Dec 1; 2005 353(22):2373-83. [PubMed: 16319386]

[67]. Greenhough A, Smartt HJM, Moore AE, et al. The COX-2/PGE2 pathway: key roles in the hallmarks of cancer and adaptation to the tumour microenvironment. Carcinogenesis. Mar; 2009 30(3):377-86. [PubMed: 19136477]

[68]. Wang D, Dubois RN. Prostaglandins and cancer. Gut. Jan; 2006 55(1):115-22. [PubMed: 16118353]

[69]. Chulada PC, Thompson MB, Mahler JF, et al. Genetic disruption of Ptgs-1, as well as Ptgs-2, reduces intestinal tumorigenesis in Min mice. Cancer Research. Sep 1; 2000 60(17):4705-8. [PubMed: 10987272]

[70]. Patrono C. Measurement of cyclooxygenase isozyme inhibition in humans: exploring the clinical relevance of biochemical selectivity. Clinical and Experimental Rheumatology. 19(6 Suppl. 25):S45-S50. [PubMed: 11695252]

[71]. Ruffin MT, Krishnan K, Rock CL, et al. Suppression of human colorectal mucosal prostaglandins: determining the lowest effective aspirin dose. Journal of the National Cancer Institute. Aug 6; 1997 89(15):1152-60. [PubMed: 9262254]

[72]. Chulada PC, Loftin CD, Winn VD, et al. Relative activities of retrovirally expressed murine prostaglandin synthase-1 and -2 depend on source of arachidonic acid. Archives of Biochemistry and Biophysics. Jun 15; 1996 330(2):301-13. [PubMed: 8660660]

[73]. Reddy BS, Rao CV, Seibert K. Evaluation of cyclooxygenase-2 inhibitor for potential chemopreventive properties in colon carcinogenesis. Cancer Research. Oct 15; 1996 56(20): 4566-9. [PubMed: 8840961]

[74]. Oshima M, Dinchuk JE, Kargman SL, et al. Suppression of intestinal polyposis in Apc delta716 knockout mice by inhibition of cyclooxygenase 2 (COX-2). Cell. Nov 29; 1996 87(5):803-9. [PubMed: 8945508]

[75]. Chan AT, Ogino S, Fuchs CS. Aspirin and the risk of colorectal cancer in relation to the expression of COX-2. The New England Journal of Medicine. May 24; 2007 356(21):2131-42. [PubMed: 17522398]

[76]. Clària J, Lee MH, Serhan CN. Aspirin-triggered lipoxins (15-epi-LX) are generated by the human lung adenocarcinoma cell line (A549)-neutrophil interactions and are potent inhibitors of cell proliferation. Molecular Medicine. Sep; 1996 2(5):583-96. [PubMed: 8898374]

[77]. Craven PA, DeRubertis FR. Effects of aspirin on 1,2-dimethylhydrazine-induced colonic carcinogenesis. Carcinogenesis. Apr; 1992 13(4):541-6. [PubMed: 1315625]

[78]. Patrono C, Patrignani P, Rodríguez LA García. Cyclooxygenase-selective inhibition of prostanoid formation: transducing biochemical selectivity into clinical read-outs. The Journal of Clinical Investigation. Jul; 2001 108(1):7-13. [PubMed: 11435450]

[79]. Ulrych T, Böhm A, Polzin A, et al. Release of sphingosine-1-phosphate from human platelets is dependent on thromboxane formation. Journal of Thrombosis and Haemostasis. Apr; 2011 9(4): 790-8. [PubMed: 21251196]

[80]. Pyne NJ, Pyne S. Sphingosine 1-phosphate and cancer. Nature Reviews. Cancer. Jul; 2010 10(7): 489-503.

[81]. Babbar N, Gerner EW, Casero RA. Induction of spermidine/spermine N1-acetyltransferase (SSAT) by aspirin in Caco-2 colon cancer cells. The Biochemical Journal. Feb 15; 2006 394(1): 317-24. [PubMed: 16262603]

[82]. Martinez ME, O’Brien TG, Fultz KE, et al. Pronounced reduction in adenoma recurrence associated with aspirin use and a polymorphism in the ornithine decarboxylase gene. Proceedings of the National Academy of Sciences of the United States of America. Jun 24; 2003 100(13): 7859-7864. [PubMed: 12810952] 
[83]. Aspirin for the prevention of cardiovascular disease: U. S. Preventive Services Task Force recommendation statement. Annals of Internal Medicine. Mar 17; 2009 150(6):396-404.

[84]. Hassan C, Rex DK, Cooper GS, et al. Primary prevention of colorectal cancer with low-dose aspirin in combination with endoscopy: a cost-effectiveness analysis. Gut. in press. 


\section{Practice Points}

- Both observational and randomized control trials support a chemopreventive benefitof aspirin for colorectal cancer.

- Doses as low as $75 \mathrm{mg} /$ day may be effective, though data are not entirely consistent.

- Aspirin's known adverse effects on gastrointestinal and intracranial bleeding currently limit its widespread use for cancer prevention.

- Emerging data suggest that the anti-neoplastic benefit of aspirin may also be relevant to other cancer sites

- Reappraisal of the risk/benefit in view of the new evidence is warranted 


\section{Research Agenda}

- The optimal dose for prevention of CRC and other cancers is not fully established.

- The anti-neoplastic mechanisms of aspirin relevant to CRC remain incompletely characterized.

- Further research into the precise effects of aspirin on colorectal carcinogenesis will be critical in informing decisions about optimal dose, frequency of administration, and combination therapy with other agents.

- Studies examining the cardiovascular and antineoplasic benefits of aspirin in relation to its adverse effects may help to fully establish its role as chemopreventive agent in specific populations. 


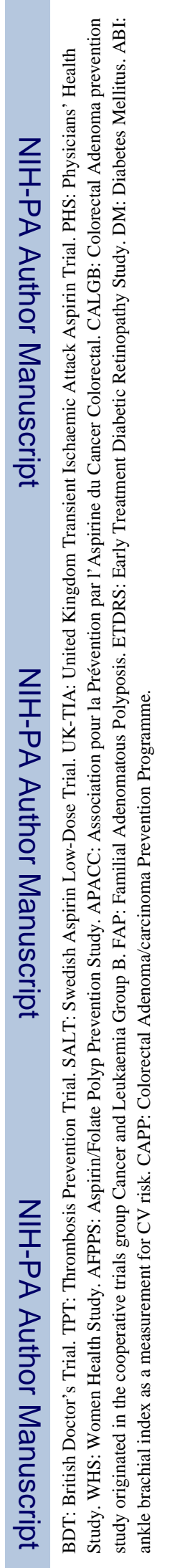

Best Pract Res Clin Gastroenterol. Author manuscript; available in PMC 2012 August 01. 